\title{
A Case of Hyperemesis Gravidarum due to Gastric Cancer Masquerading as Preeclampsia
}

\author{
Daniel R. Hersh, M.D., ${ }^{1}$ Michael A. Belfort, M.B.B.CH., M.D.Ph.D., ${ }^{2}$ \\ and G. Lance White, B.A. ${ }^{2}$
}

Nausea and vomiting are symptoms frequently seen in normal pregnancy. We report a patient with gastric carcinoma who presented with severe hyperemesis gravidarum that led to extreme volume depletion, hypertension, proteinuria, and acute renal failure. A 35-year-old woman (para 2-1-0-1) with a prenatal course significant for persistent nausea, vomiting, and poor weight gain presented at 36 weeks' gestation with elevated blood pressure $(157 / 114 \mathrm{~mm} \mathrm{Hg})$, proteinuria $(4+)$, hypochloremic metabolic alkalosis, and severe intravascular volume contraction. A presumptive diagnosis of severe preeclampsia was made, the patient was given intravenous $\mathrm{MgSO}_{4}$, and cesarean delivery was accomplished uneventfully. When significant emesis persisted in the postoperative period, esophagogastroduodenoscopy revealed an antral/prepyloric mass with a biopsy-proven poorly differentiated adenocarcinoma. To our knowledge, this is the first report of a case of hyperemesis gravidarum with gastric cancer masquerading as preeclampsia.

KEYWORDS: Gastric cancer, hyperemesis gravidarum, preeclampsia, acute renal failure

\begin{abstract}
$\mathrm{N}_{\text {ausea and vomiting are encountered in } 75 \% \text { of }}$ pregnancies and are considered part of the "presumptive evidence" for pregnancy. ${ }^{1}$ This morning sickness of pregnancy usually occurs during the morning but may continue during the day. The onset is at $\sim 6$ weeks' gestation and may last up to 16 to 20 weeks. ${ }^{1}$ In its most severe form, the patient is usually given the diagnosis of hyperemesis gravidarum, which is defined as vomiting so severe as to produce weight loss, dehydration, acidosis from starvation, alkalosis from loss of hydrochloric acid in vomitus, and hypokalemia. ${ }^{1}$ In extreme cases of volume contraction, hyperemesis gravidarum may even produce acute renal failure (ARF). ${ }^{2}$ Other causes of vomiting unrelated to the pregnancy are mostly gastrointestinal or hepatobiliary in origin, but one of the rarest
\end{abstract}

causes is cancer, especially gastric cancer. It is estimated that the incidence of cancer of the digestive tract during pregnancy is 1 in 100,000 pregnancies $^{3}$ and most are cancers of the large bowel. ${ }^{4}$ Thus, it is not surprising that gastric cancer may be overlooked in the differential diagnosis of a patient presenting with the symptoms of nausea and vomiting in pregnancy. We present an unusual case of gastric cancer that may have either precipitated or masqueraded as preeclampsia.

\section{CASE REPORT}

A 35-year-old Hispanic woman (gravida 2, para 1) presented at $36 \%$ weeks' gestation complaining of uterine contractions, spotting, decreased fetal movement,
${ }^{1}$ Queen of the Valley Medical Associates, Napa, California; ${ }^{2}$ Department of Obstetrics and Gynecology, Baylor College of Medicine, Houston, Texas.

Address for correspondence and reprint requests: Daniel R. Hersh, M.D., Queen of the Valley Medical Associates, 1100 Trancas Street, Ste. 209, Napa, CA 94558 (e-mail: dhersh01@earthlink.net).

Am J Perinatol Rep 2011;1:69-72. Copyright (C) 2011 by Thieme
Medical Publishers, Inc., 333 Seventh Avenue, New York, NY 10001, USA. Tel: +1 (212) 584-4662.

Received: December 30, 2010. Accepted after revision: March 6, 2011. Published online: June 9, 2011.

DOI: http://dx.doi.org/10.1055/s-0031-1280573.

ISSN 2157-6998. 
and nausea and vomiting. She was noted to have a blood pressure (BP) of $157 / 114 \mathrm{~mm} \mathrm{Hg}$. The fetus was in a frank breech presentation, and the fetal heart rate tracing revealed persistent late decelerations and absent beat-tobeat variability. The patient was diagnosed with severe preeclampsia, started on $\mathrm{MgSO}_{4}$, and had an urgent cesarean delivery. A healthy 2595-g male with Apgar scores of 5 and 8 at 1 and 5 minutes, respectively, and with cord arterial $\mathrm{pH}$ of 7.23 was delivered without incident. Observation of the liver surface at the time of surgery revealed no abnormalities.

The patient had received prenatal care from 11 weeks with 11 total visits. Her initial BP was $114 / 60 \mathrm{~mm}$ $\mathrm{Hg}$. Her prenatal course was remarkable for persistent significant nausea, vomiting, and poor weight gain. The patient weighed 112.5 pounds at 11 weeks, 129 pounds at 23 weeks, and 118 pounds at 34 weeks. She had been given metoclopramide, promethazine, prochlorperazine, and simethicone without relief. An ultrasound at $21^{3} / 7$ weeks confirmed her dates (estimated fetal weight $=433$ $\mathrm{g}$, 56th percentile, and no anomalies noted). There was no past medical or family history of gastrointestinal or hepatobiliary disease, and a test of her stool for ova and parasites was negative. At her initial visit at 11 weeks, her hemoglobin and hematocrit values were $8.1 \mathrm{mg} / \mathrm{dL}$ and $27.2 \%$, respectively, and her platelet count was $533,000 / \mathrm{mm}^{3}$. An anemia workup showed a normal hemoglobin electrophoresis and a serum ferritin $=9.7$ $\mathrm{ng} / \mathrm{mL}$ and total iron-binding capacity $=505 \mu \mathrm{g} / \mathrm{dL}$. On admission, her hemoglobin and hematocrit values were $18.0 \mathrm{mg} / \mathrm{dL}$ and $52.8 \%$, respectively, and her platelet count was $194,000 / \mathrm{mm}^{3}$. Her electrolytes $(\mathrm{mmol} / \mathrm{L})$ were: $\mathrm{Na}=135, \mathrm{~K}=3.5, \mathrm{CI}=77$, and $\mathrm{CO}_{2}=37.0$. Her blood urea nitrogen was $49 \mathrm{mg} / \mathrm{dL}$, creatinine was $2.7 \mathrm{mg} / \mathrm{dL}$, uric acid was $16.9 \mathrm{mg} / \mathrm{dL}$, aspartate aminotransferase was $49 \mathrm{U} / \mathrm{L}$, alanine aminotransferase was $29 \mathrm{U} / \mathrm{L}$, and albumin was $2.3 \mathrm{~g} / \mathrm{dL}$. Her prothrombin time and partial thromboplastin time were 17.6 and 46.7 seconds, respectively, and her urinalysis showed $4(+)$ proteinuria.

The patient was noted to be both volume contracted and to have a hypochloremic metabolic alkalosis. Her electrolytes were corrected with normal saline with $10 \mathrm{mEq} \mathrm{KCl}$, and these normalized by postoperative day 2. The patient was started on clear liquids on the evening of postoperative day 1 but continued to have emesis and so the gastrointestinal service was consulted. Additionally, the patient was started on hyperalimentation with total parenteral nutrition.

A flat plate of the abdomen revealed moderate gaseous distension of the stomach (Fig. 1). The differential diagnosis included intermittent small bowel obstruction, gastric outlet obstruction, or peptic ulcer disease. Contrast-enhanced axial computed tomography imaging through the abdomen revealed a dilated stomach with thickened irregular antrum and thickening of

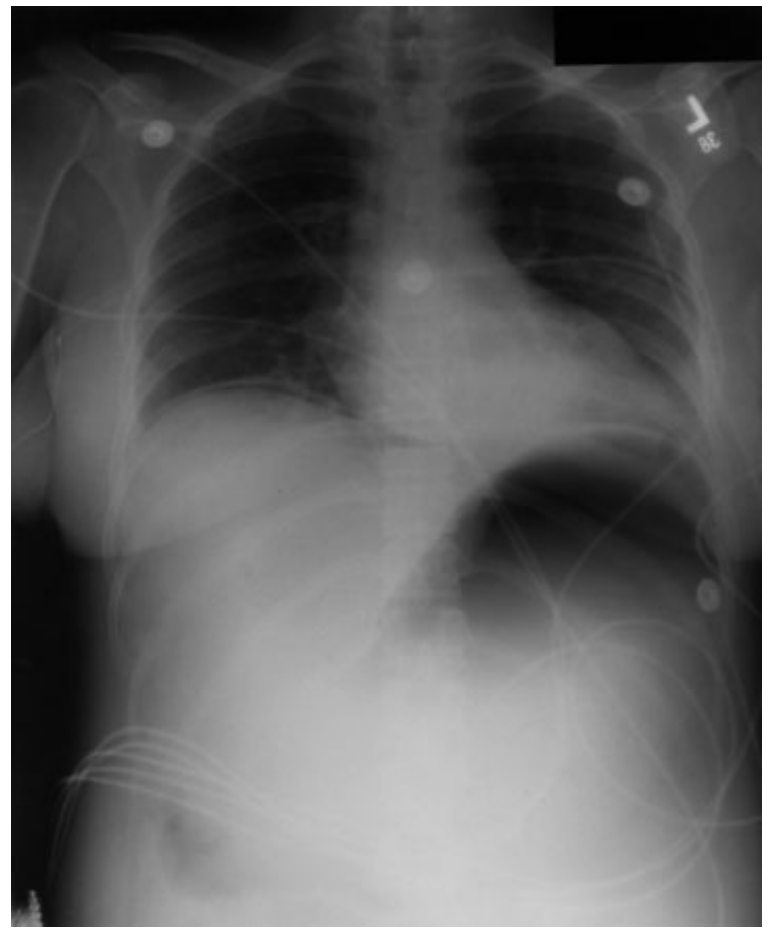

Figure 1 A flat plate of the abdomen reveals moderate gaseous distension of the stomach.

the posterior wall (Fig. 2). A nasogastric tube and famotidine were recommended. The nasogastric tube was placed (with an initial aspiration of $1400 \mathrm{~mL}$ dark green fluid) and provided immediate relief. Esophagogastroduodenoscopy revealed antral/prepyloric distortion secondary to a submucosal mass consistent with either neoplasm or infectious cause. No ulcer was seen. A biopsy showed poorly differentiated adenocarcinoma,

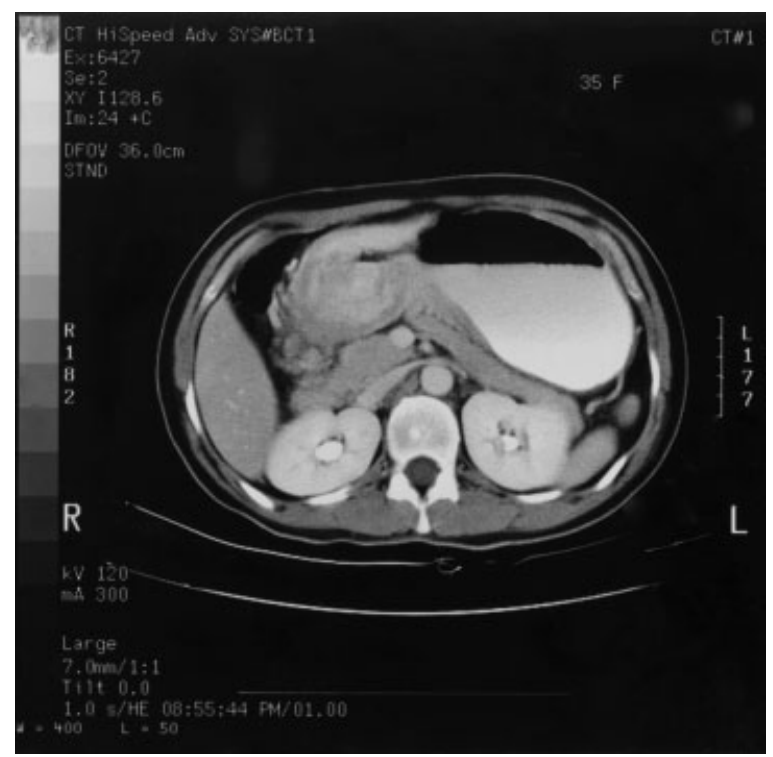

Figure 2 Contrast-enhanced axial computed tomography image through the abdomen revealing a dilated stomach with thickened irregular antrum and thickening of the posterior wall. 
and a computerized tomography scan of the abdomen revealed a $3 \times 4-\mathrm{cm}$ mass in the pylorus and no perigastric lymphadenopathy or liver metastases. The patient underwent a total gastrectomy, Roux-en-Y esophagojejunostomy, feeding jejunostomy, and omentectomy with node sampling 11 days after her cesarean delivery. She had a $12.0 \times 9.5-\mathrm{cm}$ gastric carcinoma, and 8 of 15 lymph nodes were positive (stage IIIA [T3, N1, MX]); distant metastasis was not assessed at the time of surgery.

The patient was discharged home 23 days after her initial admission. The baby was discharged home on day of life 7. The patient was alive 15 months after surgery but has since been lost to follow-up.

\section{DISCUSSION}

This was an unusual case presentation of gastric cancer in pregnancy. Because of hyperemesis gravidarum, the patient was volume contracted and had hypochloremic metabolic alkalosis. This volume contraction may have been the cause of her prerenal ARF, with resultant proteinuria and hypertension. Whether she had preeclampsia in addition to the cancer or whether the signs and symptoms were all due to her gastric cancer is unclear. It is also unknown, if she did in fact have preeclampsia and whether the ARF precipitated the preeclampsia or was the result of preeclampsia. ARF is a known complication of preeclampsia. Although hyperemesis gravidarum has been described as a cause of $\mathrm{ARF}^{2}$ a review of the literature on gastric cancer in pregnancy shows this to be a very rare cause of hyperemesis.

Preeclampsia has been mistaken for hepatitis, cholangitis, systemic lupus erythematosus, immune thrombocytopenic purpura (ITP), gastric ulcer, detached retina, and acute appendicitis. ${ }^{5}$ Because of this, it was dubbed the "great imitator" at the 1975 Pacific Coast Obstetrical and Gynecological Society. ${ }^{5}$ Goodlin suggested that the diagnosis of preeclampsia or hemolysis, elevated liver enzymes, and low platelet count (HELLP syndrome) has also been applied to processes unrelated to pregnancy. ${ }^{5}$ These diseases include cardiomyopathy, dissecting aortic aneurysm, cocaine abuse, essential hypertension and chronic renal disease, acute fatty liver of pregnancy, gangrenous or ruptured gall bladder, glomerulonephritis, ITP, lupus erythematosus, malignant pheochromocytoma, and a ruptured bile duct. ${ }^{5}$ To this list we may now add gastric cancer.

Cancer of the stomach is a very rare condition and rarer in pregnancy. ${ }^{3}$ This low incidence is obviously influenced by the fact that the peak incidence of pregnancy is below 35 years of age. ${ }^{1}$ The peak incidence of gastric cancer is in the sixth decade, and men are affected twice as frequently as women. ${ }^{6}$ In a review of the German National Cancer Registry, Haas ${ }^{7}$ demonstrated a lower incidence than expected of all cancers, including stomach cancer, in pregnant women and speculated that women with subclinical cancers do not usually become pregnant, presumably due to decreased libido resulting from constitutional symptoms. Alternatively, it was suggested that "conception, implantation, or early embryonic development could be disrupted by hormonal or immunologic concomitants of malignant disease." 7 Most of the cases are diagnosed in advanced stages either because the patient's symptoms are attributed to her pregnancy or because of a reluctance to pursue diagnostic studies during pregnancy. ${ }^{8}$ This delay may explain the poor prognosis of this malignancy. It has been suggested that persistent gastrointestinal symptoms during pregnancy should be evaluated by gastroendoscopy, ${ }^{1}$ and we endorse this recommendation. In those cases where there is persistent vomiting, electrolyte analysis and blood gas evaluation may be indicated to rule out serious disturbances and to guide therapy.

Our case suggests that gastric cancer may be a rare cause of hyperemesis in pregnancy, with ultimate renal failure and/or preeclampsia as the presenting diagnosis. Early diagnosis of this malignancy is important in improving the patient's prognosis.

\section{REFERENCES}

1. Cunningham FG, MacDonald PC, Gant NF, Leveno KJ, Gilstrap LC, eds. Williams Obstetrics. 19th ed. Norwalk, CT: Appleton \& Lang; 1991:22

2. Pertuiset N, Grünfeld JP. Acute renal failure in pregnancy. Baillieres Clin Obstet Gynaecol 1994;8:333-351

3. Woolf RB. Gastrointestinal complications of pregnancy. In: Gynecology Obstetrics Guide. Vol. 1. Chicago: Commerce Clearing House, Inc.; 1965

4. Nesbitt JC, Moise KJ, Sawyers JL. Colorectal carcinoma in pregnancy. Arch Surg 1985;120:636-640

5. Goodlin RC. Preeclampsia as the great imposter. Am J Obstet Gynecol 1994;164:1577-1581

6. Schwartz SL, Lillehci RC, Shires GT, et al. Principles of Surgery. New York: McGraw Hill Book Co.; 1974:1082-1083

7. Haas JF. Pregnancy in association with a newly diagnosed cancer: a population-based epidemiologic assessment. Int J Cancer 1984;34:229-235

8. Hirabayashi M, Ueo H, Okudaira Y, Matsumata T, Hanawa S, Sugimachi K. Early gastric cancer and a concomitant pregnancy. Am Surg 1987;53:730-732 